\title{
Monitoring the Quality of Tourism Experience
}

\author{
Júlio Mendes \\ Economics Faculty. Research Centre for Spatial \\ and Organizational Dynamics (CIEO). \\ University of Algarve. \\ Email: jmendes@ualg.pt \\ Manuela Guerreiro \\ Economics Faculty. Research Centre for Spatial \\ and Organizational Dynamics (CIEO). \\ University of Algarve. \\ Email: mmguerre@ualg.pt \\ Nelson Matos \\ School of Management, Hospitality and Tourism. \\ Research Centre for Spatial and Organizational \\ Dynamics (CIEO). \\ University of Algarve. \\ Email: nelsonmatos@gmail.com
}

\begin{abstract}
The new economic era - the experience economy - that we entered in the XXI century is challenging the overall tourism industry and destinations to respond to visitor expectations in a radically different way, demanding a new vision on what is truly being delivered to them. Within the current era, tourism businesses and destinations, in order to thrive and compete globally, are bound to recognize that experience, not goods or services, are what motivates visitors to travel, repeat visits to the destinations and recommend it to friends and relatives. Being so, a research agenda for tourism development and quality should place at its centre the nature of tourist experience and meanings of quality tourist experience from the stakeholders point of view, so that the industry actors can take joint action supported by in-depth knowledge of meanings attached to experience. With few exceptions, in tourism related literature, quality tourism experience has been largely overlooked. However, tourist experience and tourism experience have been discussed by Clawson [1], [2], [3], [4], [5], [6], [7], [8], [9] among others. Clawson[1] wrote about recreation experience; Boorstin[2] discoursed on authenticity in tourist experience; Cohen[3], [4] studied the phenomenological tourist experience frames; MacCannell's [5] presented contemporaneous writings on tourist experience and authenticity. Pearce and Caltabiano[7] further extended consideration of traveller and tourist experience and authenticity with connections to motivations. Smith [6], Smith and Brent [8] addressed the interaction of host and guest in travel experience. Ryan [9] focused particularly on the 'tourist experience'. Tourism and tourist experience past research have also focused on temporary and activity-based relationships [1] and some only on activity [10], [11]. Borrie and Birzell[12] presented four
\end{abstract}

ways used to understand tourist and tourism experience. Those four ways include (1) meaningsbased[13], (2) benefits, (3) satisfaction[14], and (4) experience based means[4], [15]. Urry[16] introduced the notion of 'gaze' into considerations of tourist experience albeit 'his gazes' were challenged by Perkins and Thorns[17]. Although there has been considerable theoretical thinking on the subject, not much empirical research is available. One reason for this to happen is the multidimensional, complex and highly diversified nature of the tourist experience. Another reason is related to the fact that supporting constructs, namely satisfaction, quality and value, continue relatively ambiguous and are not always part of an integrated vision and consistent research. And yet, understanding of major and relevant dimensions of the tourist experience are of utmost importance to construct operationalization for effective experience management at destination level. The article proposes an integrated vision on how to monitor the quality of tourism in a mass tourism coastal destination - the Algarve (Portugal). While analyzing the quality of the tourism experience from tourists' perspective represents the overall purpose of this paper, and the specific objectives are threefold. Firstly, the research intends to assess the tourists' perceptions on the four dimensions of the experience destination, attributes and compares them with satisfaction felt in terms of the same attributes. Secondly, it expects to provide an overall assessment of tourism experience. Thirdly, the study proposes to establish the relationship between tourist satisfaction and the tourist experience and destination loyalty. The questionnaires were based on the work of Oh, Fiori and Jeong [18], after having been adapted to the Algarve tourist destination context, and refer to the four areas of the Experience Economy: Education (items a, b, c, d), aesthetics (items e, f, g, h), Entertainment $(i, j, k, l)$ and Escapism $(m, n, o, p)$. The last three items - q, r, s - are related to memory and memories. To that end, a survey was carried out sampling 405 individuals. Of the 397 valid questionnaires obtained, $90 \%$ were answered by tourists from Portugal, Germany, Spain, the Netherlands, Ireland and the United Kingdom. The results show about $95 \%$ of the respondents are satisfied and very satisfied. Approximately $95.3 \%$ of the respondents say they are satisfied and very satisfied with their stay in the Algarve. About the quality of lived experience, $\mathbf{7 7 . 3 \%}$ classified very good and excellent. One of the important findings of this research is that the majority of the respondents $(93 \%)$ intends to recommend the Algarve to friends and relatives. With this research, the team expects to contribute to a thorough understanding of tangible and intangible activities and attributes that form the underlying basis of the tourist experience in coastal tourism.

Keywords: quality, tourism experience, tourism destination, satisfaction. 


\section{INTRODUCTION}

In a context of globalization and increasing competition between organizations and tourism destinations, it is important to find ways to differentiate specific and composite products in order to be successful. Fostering competitiveness in a destination entails adopting an unequivocal quality approach to meet the balance between tourists' expectations, needs and wants and the understanding of what they think and how they live experiences.

The concerns about tourist experiences have led Destinations Management Organizations to face different and more complex challenges. These challenges mean that DMO's need to develop a new vision on how the tourism system should work and to adopt new management paradigms aiming at achieving a high level of tourist satisfaction.

Understanding tourists experiences, based on the identification of perceptions and emotions tourists and visitors have during their stay at the destination, is a central issue for DMO's in terms of supply and positioning to potential segments.

Although there has been considerable theoretical thinking on the subject, not much empirical research is available. One reason for this to happen is the multidimensional, complex and highly diversified nature of the tourist experience. Another reason is related to the fact that supporting constructs, namely satisfaction, quality and value, continue relatively ambiguous and not always part of an integrated vision and consistent research. And yet, understanding of major and relevant dimensions of tourist experiences are of utmost importance to construct operationalization for effective experience management at destination level.

Researchers face many challenges and obstacles in this particular area of investigation due to difficulties in construct definition and consensus, the opportunity for multiple theoretical approaches, as well as the inherent complexity of experience-related issues, as an effect of the dynamic, subjective, emotional and contextual nature of the experience itself. In sum, the construct operationalization both for the purpose of understanding the phenomenon and for practical benefits to the industry is the team's main challenge. The analysis of the quality of the tourist experience and the identification of the relevant issues that tourism networks, partnerships and organizations need to consider in order to increase product competitiveness are the main objectives of this research. Focusing on tourist perceptions, the goal of this paper is to contribute to a thorough understanding of tangible and intangible activities and attributes that form the underlying basis of the tourist experience which involves emotions and memories.

\section{LITERATURE REVIEW}

The process by which tourists perceive, consume and remember an experience during a visit to a destination is complex and multifaceted because of the large number of actors involved in providing the experience. Consequently, the overall experience at the destination derives from piecemeal experiences, separated by time and space, from the initial departure experience to the experience of returning home. At a conceptual level, tourist experience consists of a continuous flux of related and integrated services which are acquired during a limited period of time, often in different geographic areas.

The experience is affected by a large set of factors, many of which are not directly related to the acquisition of a specific service. It is the combination of inherent factors and associated satisfaction in terms of acquired and consumed services during the holistic tourism experience which determines the overall satisfaction of tourists. Experience quality is generally recognized as more subjective in nature opposed to service quality, which has some objective dimensions. Service quality is generally connected to a specific service transaction. The wider temporal horizon experience quality highlights the hedonistic relational component that visitors establish with destinations.

The distinction between consumer satisfaction and the quality of the experience results from various aspects. Firstly, consumers need to experience the product to determine how satisfied they are with it. Quality may be perceived without effectively experiencing/consuming the product. Secondly, quality is part of a consumer's present perception, while satisfaction is based on both present and past experience. Finally, satisfaction depends on the price and value of the product or service, while quality does not.

The perceived value is described as a composite concept that reflects the continuum that is established between the variable price and the quality predicted, during which the tourist distinguishes between the benefits received and the costs incurred.

While analyzing the quality of the tourism experience from tourists' perspective represents the overall purpose of this project, and the specific objectives are threefold. Firstly, the research team intends to assess the tourists' perceptions on the destination attributes and compare them with satisfaction felt in terms of the same attributes. Secondly, it expects to provide an overall assessment of tourism experience. Thirdly, the team proposes to establish the relationship between tourist satisfaction and the tourist experience and destination loyalty.

Tourist experiences is thus understandably high and the 'stage' of outstanding quality tourism experience is the approach that is increasingly being offered as key to tourism providers' efforts to positioning themselves more effectively in the marketplace. However, the problem inherent in the implementation of such approach is associated to the elusiveness and abstractedness of the constructs 'quality' and 'experience'. Therefore it is important to study the 
conceptualization and operationalization of the quality tourism experience construct.

Quality tourism experiences are frequently referred to in literature, albeit definitions are rarely provided. Despite pervasive acknowledgment of the importance of the staging of quality tourism experiences, it is important to note that there is no universal agreed definition of the term[19]. Those definitions that appear in academic and professional literature are heterogeneous in nature. Subsequently, given that tourism providers are at the forefront of provision of quality tourism experiences, this project aims to investigate the various perspectives of the subject matter within the tourism system [20].

With few exceptions, in tourism related literature, quality tourism experiences have been largely overlooked. However, tourist experiences and tourism experiences have been discussed by some authors [1] - [9]. Clawson[1] wrote about recreation experiences; Boorstin[2] discoursed on authenticity in tourist experiences; Cohen[3], [4] studied the phenomenological tourist experiences frames; MacCannell's[5] presented contemporaneous writings on tourist experiences and authenticity. Pearce and Caltabiano[7] further extended consideration of traveller and tourist experiences and authenticity with connections to motivations. Smith[6] and Smith and Brent[8] addressed the interaction of host and guest in travel experiences. Ryan[9] focused particularly on the 'tourist experience'.

Tourism and tourist experience past research have also focused on temporality and activity-based relationships [1] and some only on activity [10], [11]. Borrie and Birzell [12] presented four ways used to understand tourist and tourism experiences. Those four ways include (1) meanings-based [13], (2) benefits, (3) satisfaction [14], and (4) experience based means [4], [15]. Urry [16],[21] introduced the notion of 'gaze' into considerations of tourist experiences albeit that 'his gazes' were challenged by Perkins and Thorns[17]. Perkins and Thorns[17] defend that both international and domestic tourists in European settler societies, such as New Zealand, participate in active forms of touristic recreation; thus gazing is only one component of the tourist experience. They go further and suggest that a better metaphorical approach to tourism is to talk about the tourist performance, which incorporates ideas of active bodily involvement, physical activity and gazing.

Quality issues have never been unfamiliar to tourism. However, it was only in the decade of 1990 that quality started to be part of the core business of tourism providers. Since then, quality has been one of the major tourism policy issues. Bearing in mind the forecasted growth of the tourism industry, together with the complexity and globalization of today's competitive business environments in tourism, quality will continue to be one of the most important sources of competitive advantage. Each tourism provider is aware of the fierce competition and increasing tourist sophistication.

Within tourism related literature, numerous studies have focused on service delivery and quality service [21], which have been influenced by Parasuraman, Zeithaml and Berry [22], [23]. The SERVQUAL [22] tool, which measures quality, is based on constructs of empathy, responsiveness, reliability, tangibles, assurance. SERVQUAL has been modified and tested in various contexts. For example, Raajpoot[24] modified SERVQUAL to develop PAKSERV, Knutson and Patton [26] used DINESERV to measuring service quality in restaurants. Caruana and Pitt [26] used INTQUAL, Khan [27] used ECOSERV to study ecotourists' quality expectations, and Knutson, Stevens, Wullaert, Patton and Yokoyama [28] used LODGSERV, a service quality index for the lodging industry.

Quality is a well-established domain in tourism practice and academia. However, despite four or five decades of studies dealing with 'quality', the term is often used in practice as a throwaway phrase without appropriate clarification or conceptualization in the context of tourism experiences. Indeed, the quality tourism experience phenomenon is characterized by complexity [29].

Nowadays, it is generally accepted that tourism is all about quality experiences instead of quality products and/or services, yet the resolution of what determines the level or quality of such experiences has been seldom researched [29].

Previous tourism related studies on quality failed to date to present suitable models to depict Quality Tourism Experience. The study of quality tourism experience is pivotal in tourism due to widespread individual wealth (at least in the western world) previously confined to the elite with the consequence that ownership of 'ordinary' products/services is no longer a distinguishing factor. Tourists are now seeking the "extraordinary".

\section{METHODOLOGY \\ A. Setting}

The Algarve is the main Portuguese tourism destination, and tourism represents its core economic activity. The Algarve is the Southeast region of Portugal, with a coastal line of around $150 \mathrm{Km}$, an area of 4,996 km2,a climate semi-mediterranic, characterized by a soft winter and a long summer, low precipitation and an annual average temperature close to $18 \mathrm{C}$ [30]. Its resident population is about 430,000 inhabitants and the region received in 2009 around 2.7 million tourists [31], mostly in the summer. Given its natural conditions, sun and beach is the main tourist product and, more recently, the golf industry has also assisting an increased growth. 


\section{B. Data Collection Instrument}

To fulfil the objectives of this study, a questionnaire was applied. The questionnaire were based on the work of Oh, Fiori and Jeong [18], after having been adapted to the Algarve tourist destination context, and refer to the four areas of the Experience Economy: Education (items a, b, c, d), aesthetics (items e, f, g, h), Entertainment (i, j, k, l) and Escapism (m, n, o, p). The last three items - q, r, s are related to memory and memories.

The questionnaires presented to tourists were available in three languages: Portuguese, English and French. They consist of 9 questions. Data was collected at Faro International Airport (departure zone).

The evaluation of question 1 was made with an agreement of 5-point scale: strongly disagree, disagree, neither agree nor disagree, agree, strongly agree and also the N/A option (not applicable). Questions 2, 3 and 4 assess the level of interesting, stimulating and excitement through a 5-point scale: None, Low, Moderate, Very and Extremely. Items in the question 5 have been added to work Oh, Fiore and Jeong [18] and are intended to assess the perceptions of tourists on public safety, road conditions, the cleanliness, the hospitality of the residents, air quality and areas bathing. The evaluation of these items was made with an agreement of 5-point scale: strongly disagree, disagree, neither agree nor disagree, agree, strongly agree and also the N/A option (not applicable).

Question 6 discriminate the activities that the Algarve destination offers to its visitors. To assess the levels of satisfaction with this activities was used a 5-point satisfaction scale: very dissatisfied, dissatisfied, neither dissatisfied nor satisfied, satisfied, very satisfied and still not applicable option, N/A, where the visitor has not experienced the activity in question.

By question number 7 is intended to review the overall satisfaction with the stay in the Algarve, using the scale already described in the previous section. The question number 8 evaluates the perception of the tourist about the overall quality of their experience using the following 5-point scale: very poor, poor, fair, very good and excellent. The question number 8 measures the intention to recommend the Algarve to friends and family using the following scale: very unlikely, unlikely, neutral, and likely, very likely.

For the definition of the sample size, it was used the website Http://www.raosoft.com/samplesize.html. Taking into account the total number of passenger arrivals at Faro airport, 2,775,373, between 1 January and 31 December 2011, an error margin of 5\%, a confidence level of $95 \%$ and recital $50 \%$ the response distribution, the minimum sample size is 385 tourists.

To that end, a survey was carried out sampling 405 individuals. Of the 397 valid questionnaires obtained, 90\% were answered by tourists from Portugal, Germany, Spain, the Netherlands, Ireland and the United Kingdom.

\section{RESULTS}

A total of 397 valid responses were considered for the analysis. The main characteristics of the respondents reveal regarding the gender a higher percentage of female $(53 \%)$ than male $(47 \%)$. A greater difference in percentage was noted about the samples' respondents marital status, with $73 \%$ been married or living with a partner, while $21 \%$ stated to be single and $5 \%$ to have another civil status. The mean age was 41 (median $=42$, std $=14,93)$, the majority had more than high school as level of education, and were predominately $99 \%$ employed. The sample level of income was overall high, with most of the respondents stating to have more than $5000 €(37 \%)$, or with an income between $4000 €$ and $5000 €(23 \%)$. The data collected from the survey allowed to assess the destination overall quality, interest and stimuli, the experience provided to the respondents. In addition, the survey sought to evaluate the tourists' degree of satisfaction with the holidays at the setting and their recommendation intentions. As the figure I shows, Pine \& Gilmore's [32] four realms of the experience (Entertainment, Educational, Escapist, Aesthetic) was used to assess the tourism experience at the region. 
FIGURE I - Algarve TOURISTIC EXPERIENCE EVALUATION

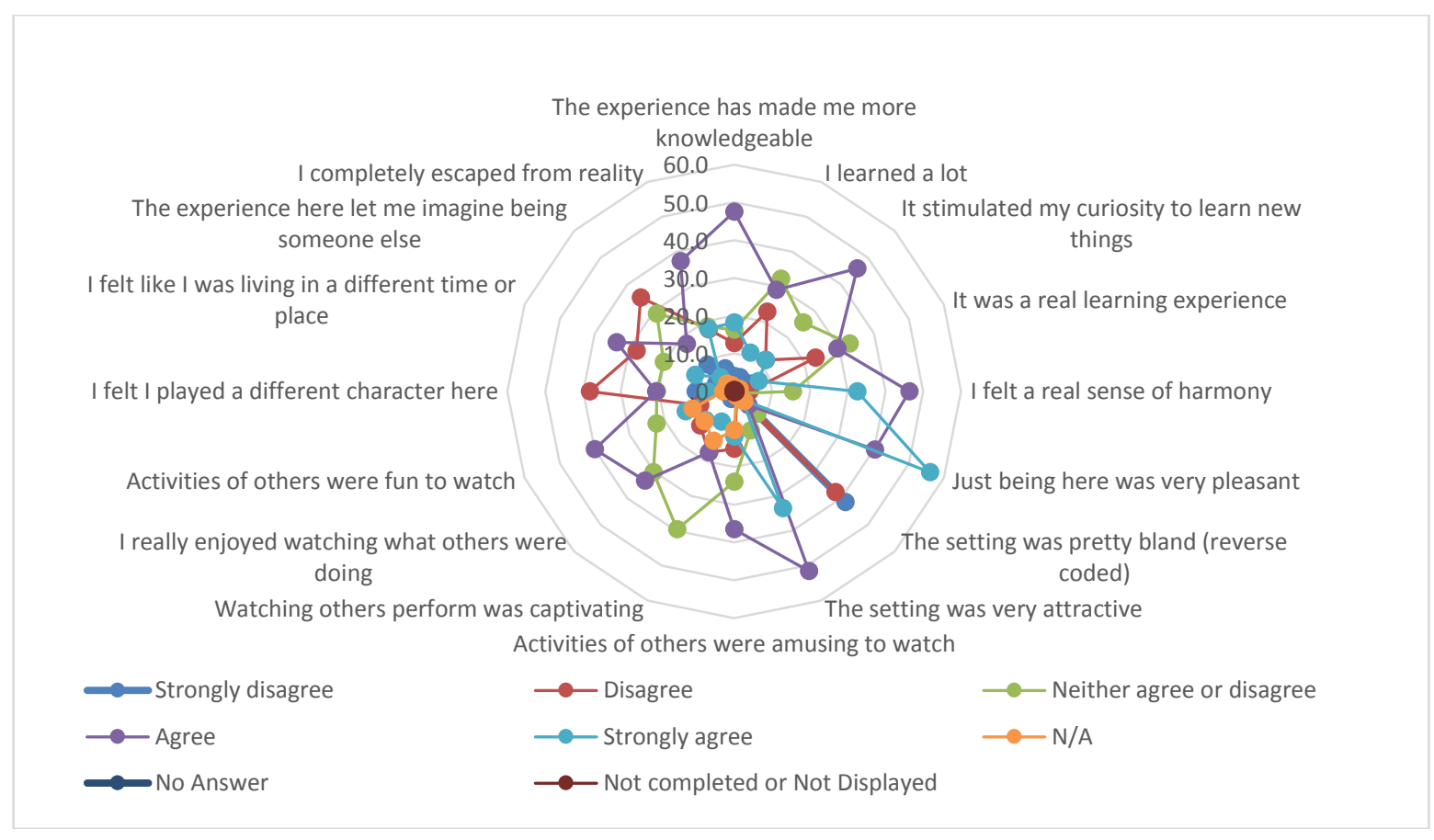

In general, the respondents considered their holidays at the setting as agreeable, in particular they expressed "the setting was very attractive" (52\%), and also that "the experience made me more knowledge" (48\%), while "I felt a real sense of harmony" (46\%) and "it stimulated my curiosity to learn new things" (46\%). However, not all the respondents had the same perception about their experience, since Neither to agree or disagree was repeated several times regarding several aspects of the experience, e.g., "watching other perform was captivating" (40\%), "it was a real learning experience" (33\%) and "I learned a lot" (33\%). For some tourists, the disagreement was expressed regarding "I felt I played a different character here" $(38 \%)$, "the setting was pretty bland" (38\%) and "the experience here let me imagine being someone else" $(35 \%)$.

Nevertheless, two categories to which they strongly agreed were "just being here was very pleasant" $(56 \%)$, followed by "the setting was very attractive"
(34 \%). This reveals respondents valued their experience, which contained all in all, tourists' engagement (immersion or absorption) and participation (passive or active). More precisely, the tourists indicated the attractiveness of the setting (aesthetic category), the opportunity to be stimulated to learn new things (education) and also the sense of harmony (escapist) while enjoying the others' activities (entertainment) as the most agreeable experiences.

Respondents were also asked if they had found their stay at the Algarve interesting (figure II), the answer led to most of them (56\%) replying positively (moderately) interesting. Moreover, of the 397 tourists that reply to the survey, $33 \%$ considered it very interesting and only $5 \%$ opined to be extremely interesting. Despite the respondents' perception of their stay not being very $(33 \%)$ or extremely interesting $(5 \%)$, but instead only moderately $(56 \%)$, the results demonstrated that solely $5 \%$ consider their stay to be slightly $(5 \%)$ or even, not all interesting $(1,25 \%)$. 
FIGURE II - HOW INTERESTING WAS YOUR STAY

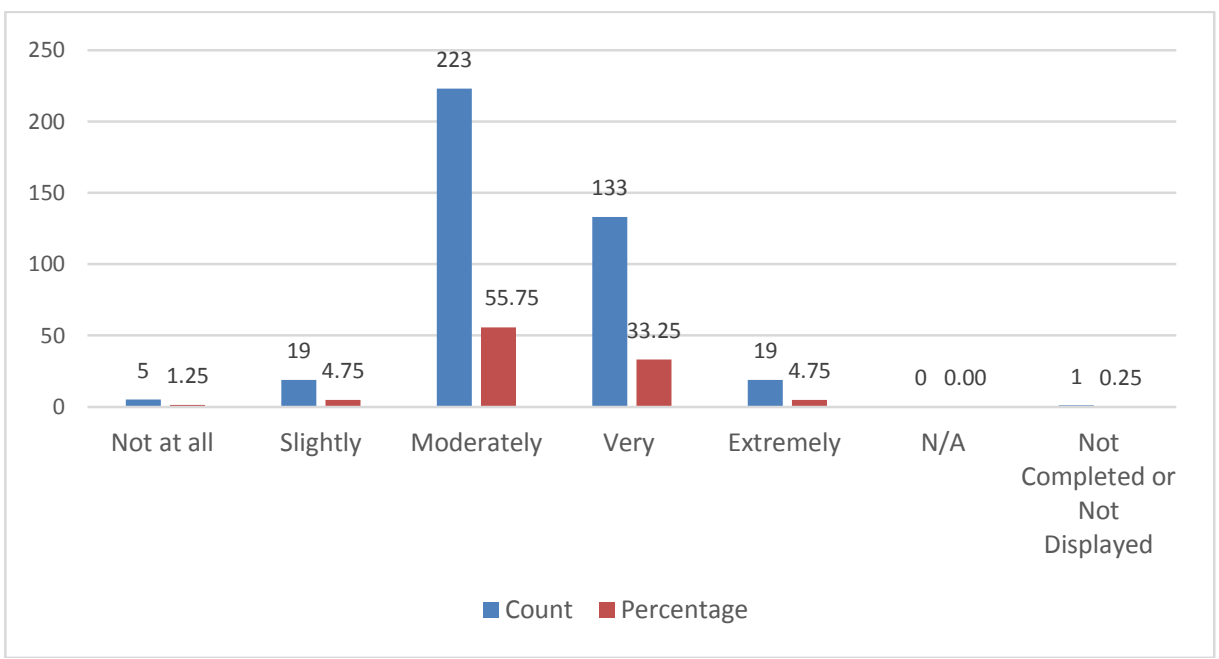

Similar results were found regarding how stimulating the stay was in the Algarve, and as figure III demonstrates, globally tourists considered the holidays very $(58 \%)$, extremely $(20 \%)$ or even moderately (20\%) stimulating. A more negative comment was given by $1,50 \%$, which rated the stay only as slightly stimulating.

FIGURE III - HOW STIMULATING WAS YOUR STAY IN THE ALGARVE?

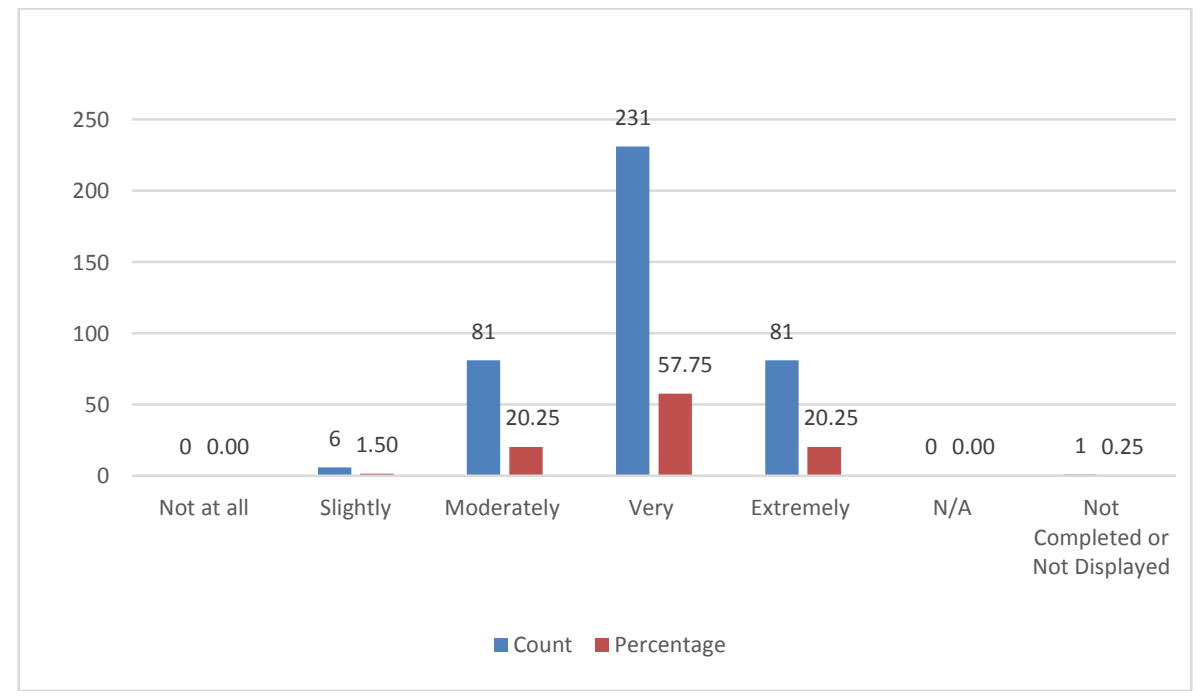

The majority of the respondents replied to agree that the overall quality of the available space $(63 \%)$, cleanliness $(62 \%)$ at the beach along with the safety $(57 \%)$ experienced during walking, but also the cleanliness of the streets $(53 \%)$ and good traffic conditions $(53 \%)$ at the Algarve, as the most dominant aspects of the quality of the setting (Figure IV). However, only less than half the respondents strongly agreed about people in the area are friendly (46\%) and hospitable (40\%), and the air to be quite clean $(45 \%)$. The aspects of the quality to which tourists decided to neither agree or disagree and also disagree, were in both cases the street signs not to be very clear and useful (16\% and $17 \%)$ and also the traffic conditions (14\% and $17 \%$, respectively). 
FIGURE IV - QUALITY OF THE EXPERIENCE (\%)

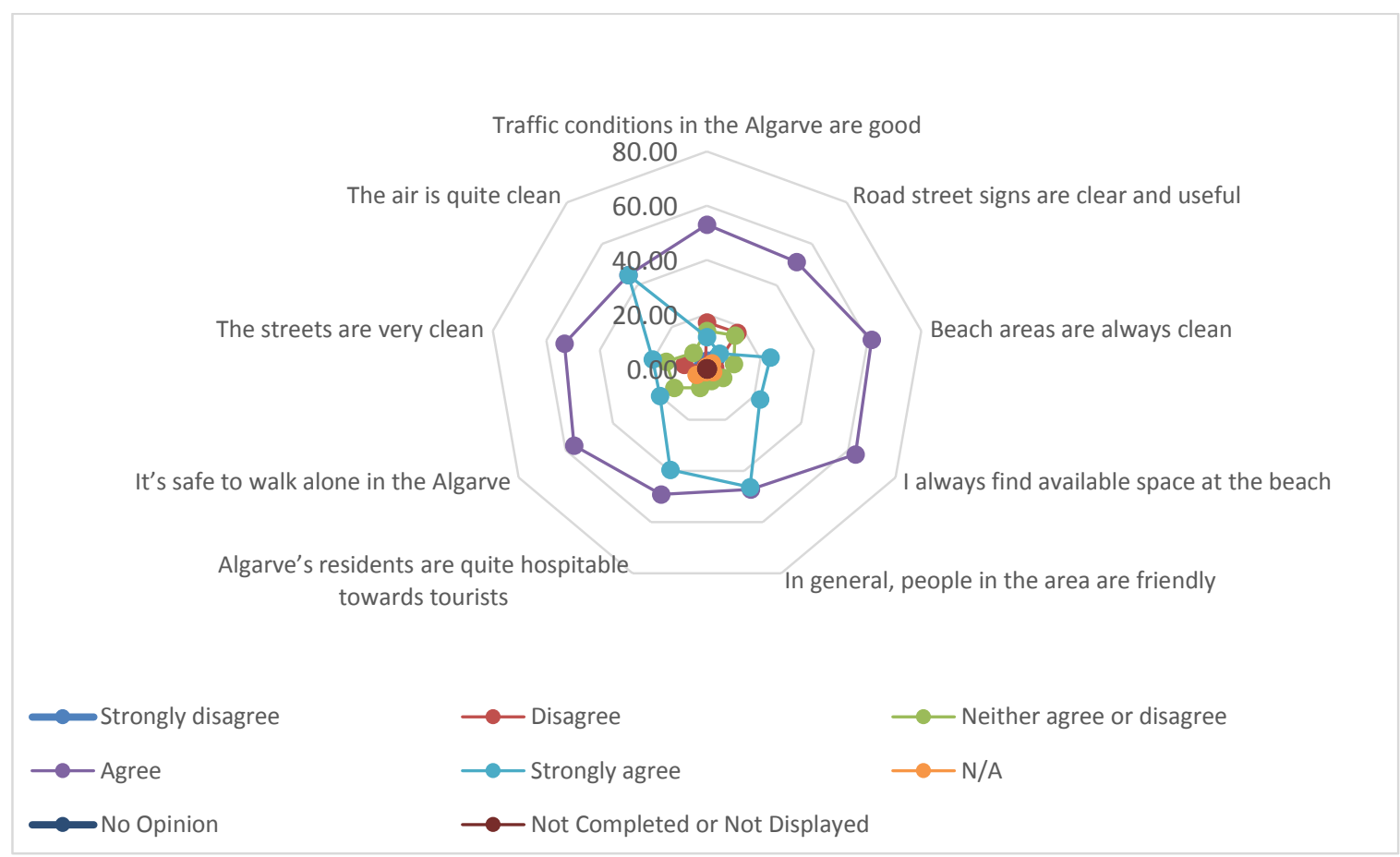

Tourists were also questioned about the most satisfying aspects of their experience (figure V) and their answer was accommodation (70\%), Bars and restaurants (66\%) and Shopping (43\%).

FIGURE V - HOW SATISFY WERE YOU WITH...

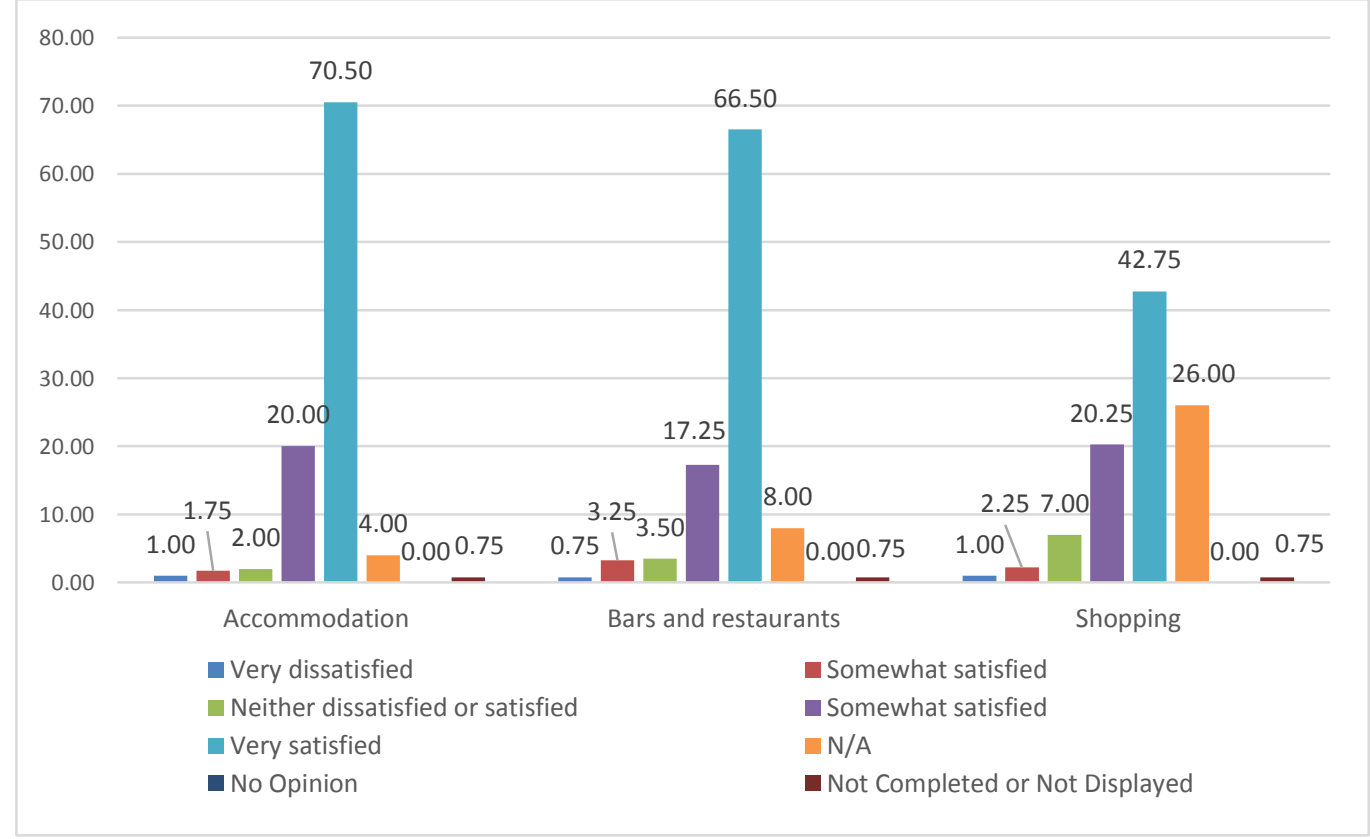

Another aspect of the experience surveyed was the tourists' satisfaction (Figure VI), with $72 \%$ indicating to be very satisfied and $23 \%$ somewhat satisfied. Only a total of $4 \%$, indicated to be very dissatisfied $(1 \%)$, somewhat satisfied $(1,5 \%)$, or neither dissatisfied nor satisfied $(1,5 \%)$. 
FigURE VI - OVERALL, HOW SATISFIED WERE YOU WITH YOUR STAY IN THE ALGARVE?

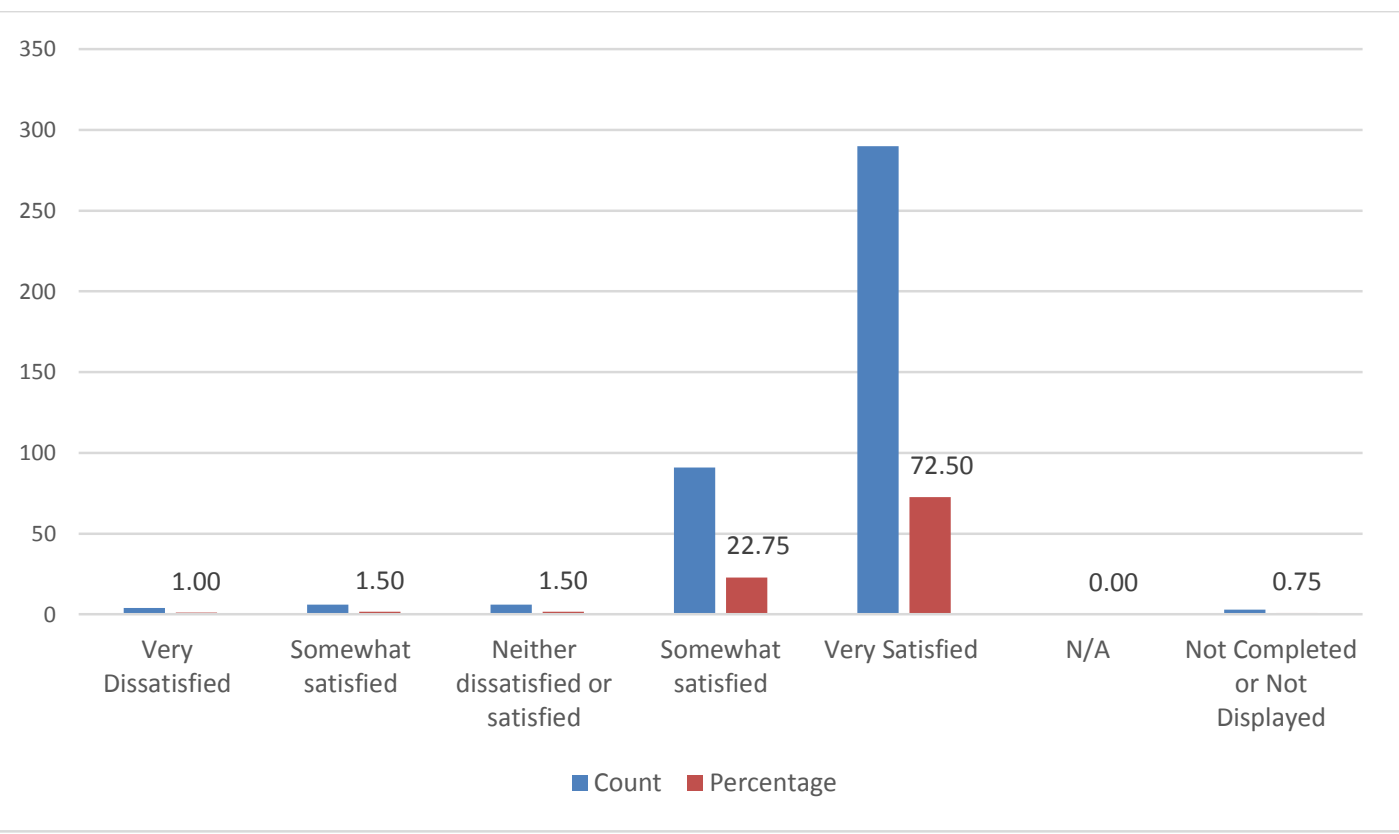

Similar opinion was expressed regarding the overall experience (figure VII), with $49 \%$ demonstrating to be mostly satisfied and $46 \%$ to be delighted with Algarve's overall experience.

FIGURE VII - What WAS your OVERALL EXPERIENCE AT THE AlgarVE?

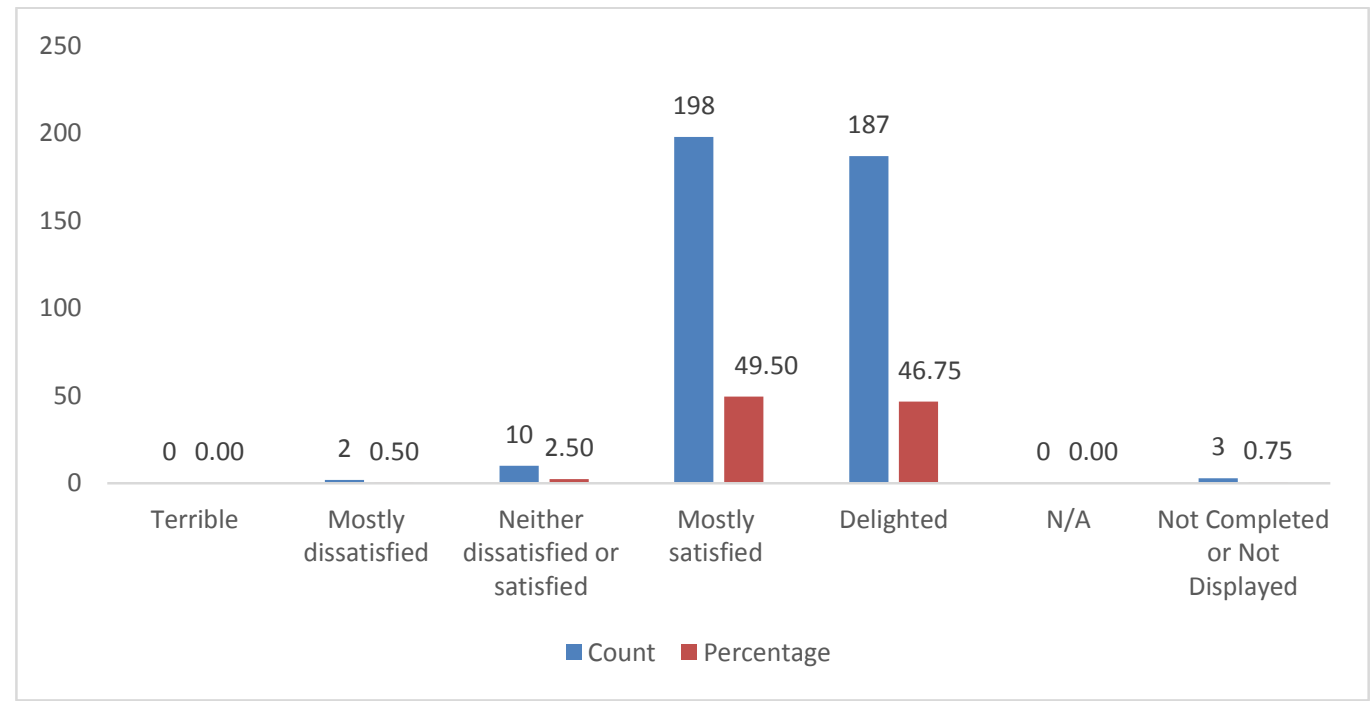

The quality of the experience was rated in general by the respondents as good (57\%), or very good (20\%). Nevertheless, there is still space for improvements from the setting side, since $21 \%$ consider it only as fair (Figure VIII). 
FIGURE VIII- How WOULD You RATE THE QUALITY OF THE EXPERIENCE AT THE AlgARVE?

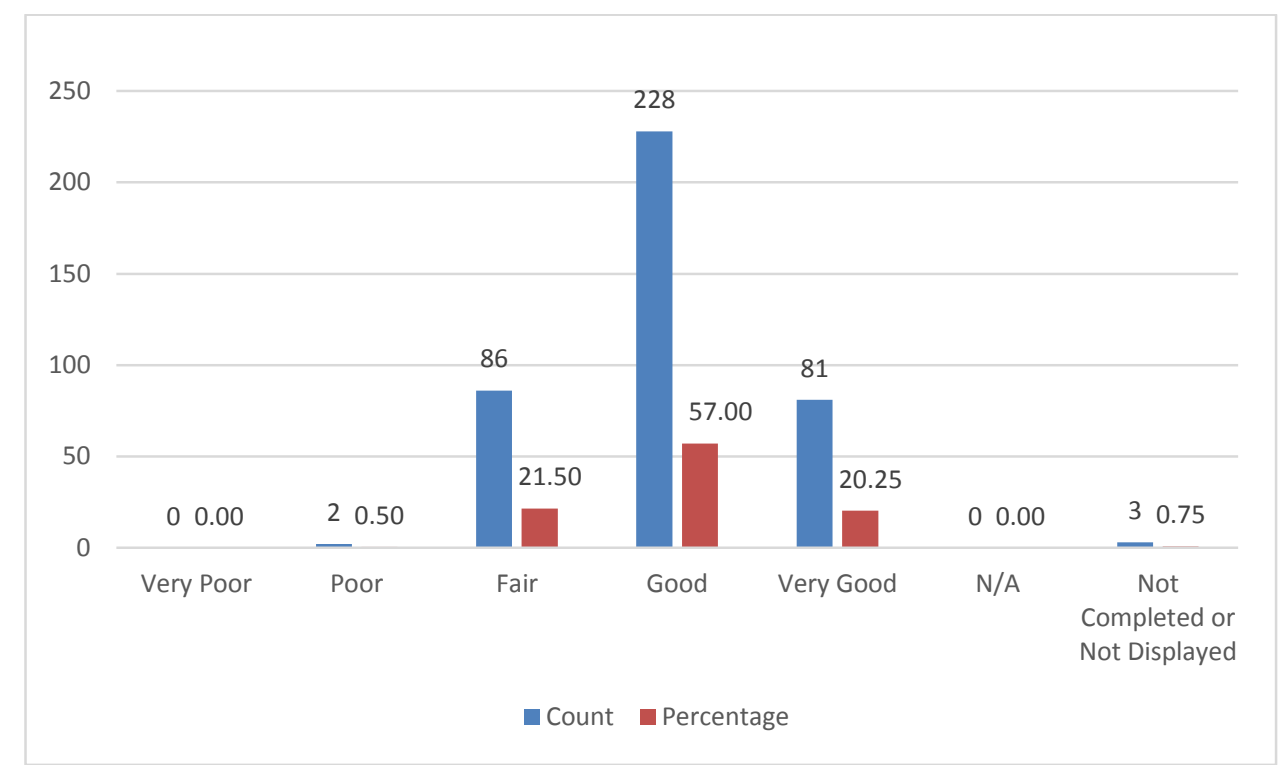

One very positive outcome of the experience at the Algarve, is the likely of $71 \%$ of the respondents in recommending the destination in the future to friends and family, in contrast to $22 \%$ (somewhat likely) which were not certain if they would recommend it (Figure IX).

FIGURE IX - HOW LIKELY IS IT THAT YOU WOULD RECOMMEND THE ALGARVE TO YOUR FRIENDS AND FAMILY?

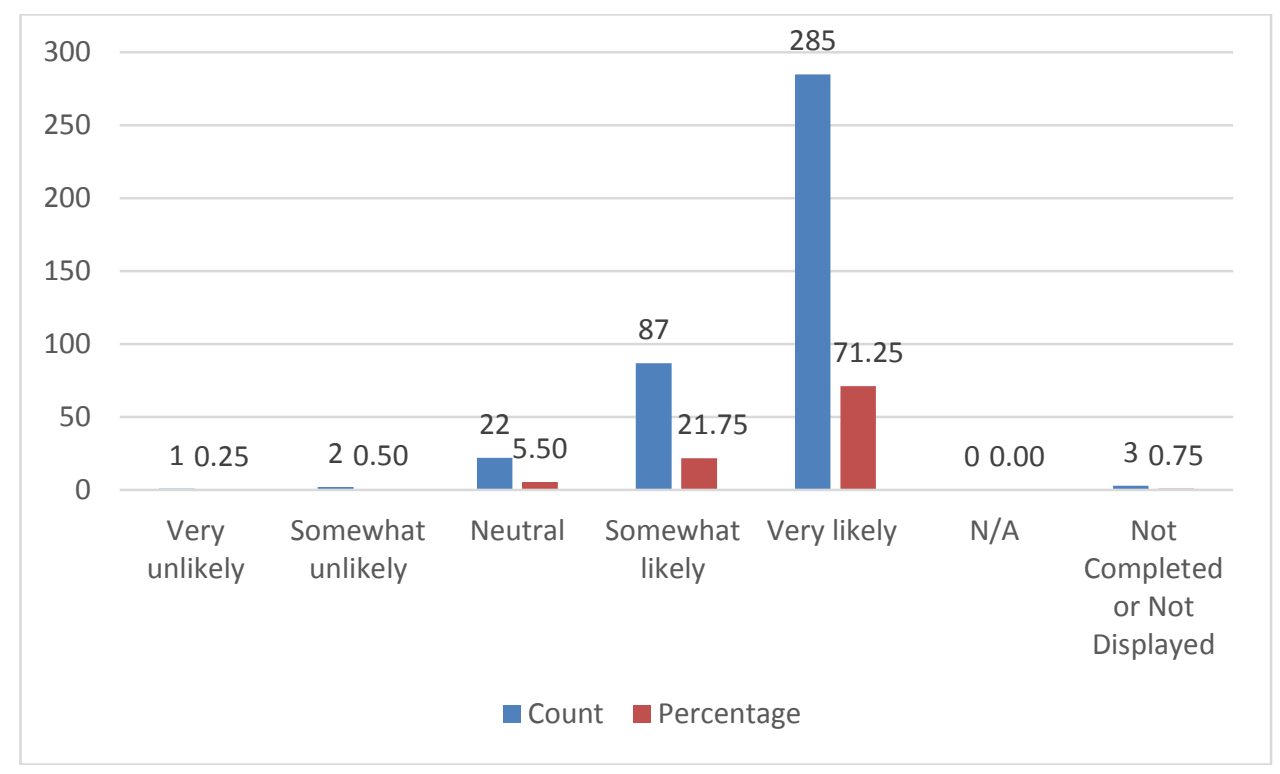




\section{V.CONCLUSION}

Quality has become a basic strategic tool for differentiation of specific and composite tourism products. Provide quality service at all levels is considered an essential strategy for success of organizations and tourist destinations in a competitive environment. The search for competitive advantages through better quality products for tourists is an undisputed issue in literature. The study of quality tourism experience is pivotal in tourism due to widespread individual wealth (at least in the western world) previously confined to the elite with the consequence that ownership of 'ordinary' this research is that the majority of the respondents (93\%) intends to recommend the Algarve to friends and relatives. With this research, the team expects to contribute to a thorough understanding of tangible and intangible activities and attributes that form the underlying basis of the tourist experience in coastal tourism destinations.

\section{REFERENCES}

[1] M. Clawson, Land and water for recreation: Opportunities, problems and policies, Chicago: Rand McNally, 1963.

[2] D. Boorstin, The image: a guide to pseudo events in America, New York: Harper and Row, 1964.

[3] E. Cohen, "Toward a sociology of international tourism," Social Research, vol. 39(1), pp. 164-182, 1972.

[4] E. Cohen, "A phenomenology of tourist experiences," Sociology, vol. 13(2), pp. 179-201, 1979.

[5] D. MacCannell, "Staged authenticity: arrangements of social space in tourist settings," American Journal of Sociology, vol. 79(3), pp. 589-603, 1973.

[6] V. Smith, Host and Guests: the Anthropology of Tourism, Philadelphia: University of Pennsylvania, 1977.

[7] P. Pearce and M. L. Caltabiano, "Inferring travel motivations from travellers' experiences," Journal of Tourism Research, vol. 17, pp. 337-352, 1982.

[8] V. Smith and M. Brent, Hosts and guest revisited: tourism issues in the 21st century, Elmsford, NY: Cognizant Communication, 2001.

[9] C. Ryan, The tourist experience. London: Continuum, 2002.

[10] R. Mclntosh, Tourism: Principles, Practices, Philosophies, Colombus: Grid, 1977.

[11] J. Crompton, "Motivations for Pleasure Vacation," Annals of Tourism Research, vol. 6(4), pp. 408-424, 1979.

[12] W.T. Borrie, and R.M. Birzell, "Approaches to measuring quality of the wilderness experience," in Visitor use density and wilderness experience: proceedings, Missoula, 2001. products/services is no longer a distinguishing factor. Tourists are now seeking the "extraordinary".

Our findings contribute to the confirmation of this statement. In accordance with the answers of the respondents, the experience is "interesting" but not so much "stimulating", what means that was not yet "extraordinary" for them. The results show about $95 \%$ of the respondents are satisfied and very satisfied with their stay in the Algarve. About the quality of lived experience, $77.3 \%$ classified very good and excellent. One of the important findings of

[13] D. Botterill and J. Crompton, "Two case studies: exploring the nature of the tourist's experience.," Journal of Leisure Research, vol. 28(1), pp. 57-82, 1996.

[14] J.Lounsbury, and J. Polik, "Leisure needs and vacation satisfaction," Leisure Sciences, vol. 14(1), pp. 105-119, 1992.

[15] W. T. Borrie and J. W. Roggenbuck, "The dynamic, emergent, and multi-phasic nature of on-site wilderness experiences," Journal of Leisure Research, vol. 3(2), pp. 202-228, 2001.

[16] J. Urry, The tourist gaze, leisure and travel in contemporary societies, London, UK: SAGE Publications, 1990.

[17] H. C. Perkins, and D. C. Thorns, "Gazing or performing?," International Sociology, vol. 16(2), pp. 185-204, 2001.

[18] H. Oh, A. Fiore, and M. Jeong, "Measuring Experience Economy Concepts: Tourism Applications," Journal of Travel Research, pp. 46119, 2007.

[19] G. Jennings, "Quality Tourism Experiences - An Introduction," in Quality Tourism Experiences, G. Jennings and N. Nickerson, Ed., Burlington, Elsevier, 2006, pp. 1-21.

[20] N. Leiper, "The framework of tourism: towards a definition of tourism, tourist, and the tourism Industry," Annals of Tourism Research, vol. 6(4), pp. 390-407, 1979.

[21] J. Urry, The Tourist Gaze, 2nd ed., London: Sage Publications, 2002

[22] G. R. Fick, and J. R. B. Ritchie, "Measuring service quality in the travel and tourism industry," Journal of Travel Research, vol. 30(2), pp. 2-9, 1991. 
[23] A. Parasuraman, V. A. Zeithaml, and L.L. Berry, "SERVQUAL: A Multi-Item Scale for Measuring Customer perceptions of Service Quality," Journal of Retailing , vol. 64(1), pp. 12-40, 1988.

[24] A. Parasuraman, L.L. Berry, and V. A. Zeithaml, "Refinement and Reassessment of the SERVQUAL Scale," Journal of Retailing , vol. 67(1), pp. 39-48, 1991.

[25] N. Raajpoot, "Reconceptualizing service encounter quality in non-western context," Journal of Service Research, vol. 7(2), pp. 181-201, 2004.

[26] P. Stevens, B. Knutson and M. Patton, "DINESERV: a tool for measuring service quality in restaurant," Cornell Hotel and Restaurant Administration Quarterly, vol. 36(2), pp. 56-60, 1995.

[27] A. Caruana, and L. Pitt, "INTQUAL - An internal measure of service quality and the link between service quality and business performance," European Journal of Marketing, vol. 31(8), pp. 604616, 1997.
[28] M. Khan, "ECOSERV: ecotourists' quality expectations," Annals of Tourism Research, vol. 30 (1), pp. 109-124, 2003.

[29] B. Knutson, P. Stevens, C. Wullaert, M. Patton, and Yokoyama, "LODGSERV: a service quality index for the lodging industry," Hospitality Research Journal, vol. 14(2) , pp. 277-284, 1990.

[30] G. R. Jennings, and N. Nickerson, Eds, Quality Tourism Experiences, Oxford, UK: Elsevier Butterworth-Heinemann, 2009.

[31] Statistics Portugal, INE, Lisbon, 2008.

[32] Statistics Portugal, INE, Lisbon, 2010.

[33] B. J. Pine, and J. H. Gilmore, The experience economy: work is theatre \& every business a stage, Harvard Business Press, 1999.

[34] A. Parasuraman, V. A. Zeithaml and L. L. Berry, "A Conceptual Model of Service Quality and Its Implications for Future Research," Journal of Marketing, vol. 49(4), pp. 41-50, 1985. 